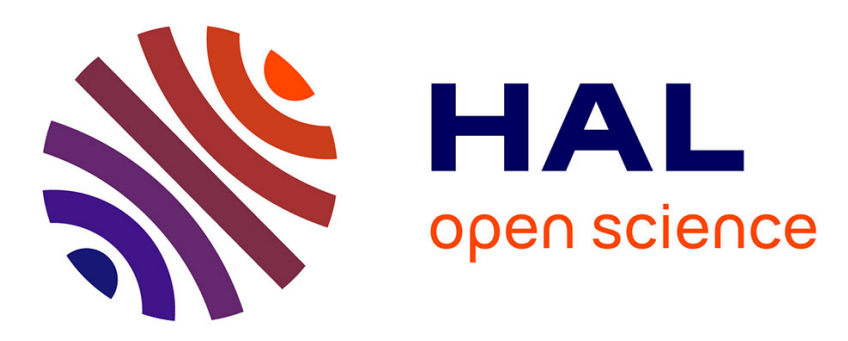

\title{
Interaction of $\mathrm{Ca} 2+$ with Uracil and its Thio Derivatives in the Gas Phase
}

Cristina Trujillo, Al Mokhtar Lamsabhi, Otilia Mó, Manuel Yáñez, Jean-Yves Salpin

\section{- To cite this version:}

Cristina Trujillo, Al Mokhtar Lamsabhi, Otilia Mó, Manuel Yáñez, Jean-Yves Salpin. Interaction of Ca2+ with Uracil and its Thio Derivatives in the Gas Phase. Organic \& Biomolecular Chemistry, 2008, 6, pp.3695-3702. 10.1039/B810418B . hal-00331703

\section{HAL Id: hal-00331703 https://hal.science/hal-00331703}

Submitted on 8 Oct 2018

HAL is a multi-disciplinary open access archive for the deposit and dissemination of scientific research documents, whether they are published or not. The documents may come from teaching and research institutions in France or abroad, or from public or private research centers.
L'archive ouverte pluridisciplinaire HAL, est destinée au dépôt et à la diffusion de documents scientifiques de niveau recherche, publiés ou non, émanant des établissements d'enseignement et de recherche français ou étrangers, des laboratoires publics ou privés. 


\section{Interaction of $\mathrm{Ca}^{2+}$ with Uracil and its Thio Derivatives in the Gas Phase}

Cristina Trujillo ${ }^{\mathrm{a}}, \mathrm{Al}$ Mokhtar Lamsabhi ${ }^{\mathrm{a}}$, Otilia Mó $^{\mathrm{a}}$, Manuel Yáñez $^{\mathrm{a}}$ and Jean-Yves Salpin ${ }^{\mathrm{b}}$

a Departamento de Química, C-9. Universidad Autónoma de Madrid. Cantoblanco, 28049Madrid. Spain

${ }^{\mathrm{b}}$ Université d'Evry Val d'Essonne - Laboratoire d'Analyse et Modélisation pour la Biologie et l'Environnement (LAMBE)

CNRS - UMR 8587 - Bâtiment Maupertuis, Boulevard François Mitterrand, 91025 Evry, France

\section{Graphic for the Table of Contents}

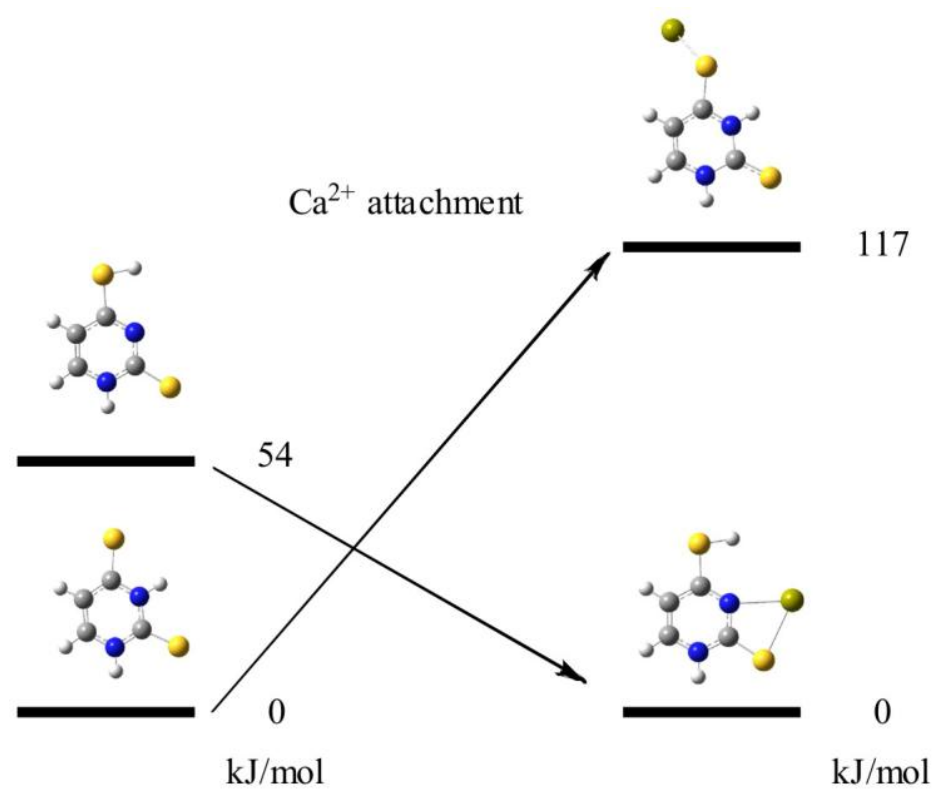

The relative stability of the different tautomers of uracil and its thio-derivatives changes completely upon $\mathrm{Ca}^{2+}$ association, the enolic tautomers becoming the most stable species. Furthermore, $\mathrm{Ca}^{2+}$ has an important catalytic effect on the corresponding tautomeric processes. 


\begin{abstract}
:
The structures and relative stabilities of the complexes formed by uracil and its sulfur derivatives, namely, 2-thio-, 4-thio, and 2,4-dithio-uracil when interacting with $\mathrm{Ca}^{2+}$ in the gas phase have been analyzed by means of density functional theory (DFT) calculations carried out at the B3LYP/6-311++G(3df,2p)//B3LYP/6-31+G(d,p) level. For uracil and 2,4dithiouracil, where the two basic sites are the same, $\mathrm{Ca}^{2+}$ attachment to the heteroatom at position 4 is preferred. However, for the systems where both types of basic centers, a carbonyl or a thiocarbonyl group, are present $\mathrm{Ca}^{2+}$-oxygen association is favored. The most stable complexes correspond to structures with $\mathrm{Ca}^{2+}$ bridging between the heteroatom at position 2 of the 4-enol (or the 4-enthiol) tautomer and the dehydrogenated ring nitrogen, N3. The enhanced stability of these enolic forms is two-folded, on one hand $\mathrm{Ca}^{2+}$ interacts with two basic sites and on the other triggers a significant aromatization of the ring. Besides, $\mathrm{Ca}^{2+}$ association has a clear catalytic effect on the tautomerization processes which connect the oxo-thione forms with the enol-enthiol tautomers. Hence, although the enol-enthiol tautomers of uracil and its thio derivatives should not be observed in the gas phase, the corresponding $\mathrm{Ca}^{2+}$ complexes are the most stable species and should be accessible, because the tautomerization barriers are smaller than the $\mathrm{Ca}^{2+}$ binding energies.
\end{abstract}

\title{
Introduction:
}

Metal dications, play a relevant role in a great variety of biological processes. However little was known on the mechanisms, at the molecular level, involved in these processes until very recently, ${ }^{1-10}$ and most of the information available is related to the interaction energies and the structure of the complexes. ${ }^{11-22}$ One of the reasons behind this lack of knowledge on how a doubly charged metal interacts with neutral systems, is the difficulty of generating stable adducts in the gas-phase. As a matter of fact, in general, when a dication, $\mathrm{M}^{2+}$, such as $\mathrm{Cu}^{2+}, \mathrm{Ni}^{2+}$ or $\mathrm{Pb}^{2+}$ interacts in the gas phase with a molecular base, 
$\mathrm{B}$, it triggers the deprotonation of the base, so that only $[(\mathrm{B}-\mathrm{H}) \mathrm{M}]^{+}$monocations are usually detected after the interaction. ${ }^{23-25}$ This seems to be related to the high recombination energies of these doubly charged metal ions, which oxidize the base, and facilitate its deprotonation. ${ }^{26 \text {, }}$ ${ }^{27}$ The situation is different when dealing with alkaline-earth metal dications such as $\mathrm{Ca}^{2+}$, whose recombination energy is significantly lower than the those of the metal dications mentioned above. As a matter of fact, the adducts between $\mathrm{Ca}^{2+}$ and different bases, such as urea $^{2}$ glycine ${ }^{5}$ thiourea ${ }^{8}$ and selenourea ${ }^{10}$ could be produced and detected using gas phase electrospray ionization/mass spectrometry techniques. ${ }^{28}$ But, what is more important, the unimolecular reactivity of these adducts could be investigated. This opened then, the possibility of analyzing the mechanisms that dictate the intrinsic reactivity of these molecules when associated with a metal dication, and in particular the role that coulomb explosions play in the observed reactivity. $2,5,8,10,29$

In our continued effort to investigate the reactions between small systems of biological relevance and $\mathrm{Ca}^{2+}$, we have considered as good candidates uracil and its thioderivatives. Uracil is an important component of nucleic acids, and 2-thiouracil and 4thiouracil have been identified as minor components of t-RNA. ${ }^{30}$ The latter are also constituents of anticancer and antithyroid drugs. ${ }^{30}$ But perhaps one of the most important characteristics of this set of compounds is its possible implication in the mutations that can occur during DNA duplication. As a matter of fact, uracil and thiouracil derivatives present many different tautomeric forms, and although it is well established that, by far, the most stable forms in the gas phase are the oxo-thione tautomers ${ }^{31-36}$, their tautomerization seems to be essential in mutagenic processes. The aim of this paper is to investigate the structure and stability of the complexes between $\mathrm{Ca}^{2+}$ and the different tautomers of uracil and its three thio-derivatives, in order to analyze the effect that the association with this divalent 
metal cation, which is ubiquitous in biological media, may have on the tautomerization processes.

\section{Computational Details}

The geometries of all possible complexes between uracil and thiouracils with $\mathrm{Ca}^{2+}$ have been optimized in the frame of the density functional theory (DFT). For this purpose we have chosen the hybrid functional $\mathrm{B} 3 \mathrm{LYP}^{37,38}$ as implemented in the Gaussian 03 suite of programs ${ }^{39}$ because, in a previous assessment ${ }^{40}$, it has been shown to provide reliable results when dealing with $\mathrm{Ca}^{2+}$ interactions. Due to the size of the systems investigated, the basis set used in ref. 39 is impractical here and we have used instead the $6-31+G(d, p)$ basis set expansion. Nevertheless, in order to ensure the reliability of the relative stability of the different tautomers, the final energy of each of the systems investigated was obtained in single-point calculations using a much larger and flexible 6-311++G(3df,2p) basis. Harmonic vibrational frequencies were computed at the same level used for the geometry optimizations in order to estimate the corresponding zero-point vibrational energy (ZPVE) corrections (scaled by 0.986$)^{41}$ and to classify stationary points of the potential energy surface either as local minima or transition states (TS). $\mathrm{Ca}^{2+}$ binding energies, $\mathrm{D}_{0}$, were evaluated by subtracting from the energy of the most stable adduct the energy of the neutral and that of $\mathrm{Ca}^{2+}$, after including the corresponding ZPVE corrections.

The binding characteristics were analyzed primarily by using the Becke and Edgecombe electron localization function $(\mathrm{ELF})^{42}$ topological approach. ${ }^{43}$ ELF has been originally conceived as a local measure of the Fermi hole curvature around a reference point. A Lorentz transform, allows ELF to be confined in the [0,1] interval, where 1 corresponds to regions dominated by an opposite spin pair or by a single electron. In this way the molecular space can be partitioned in basins, so that the valence shell of a molecule can be described in 
terms of two types of basins: polysynaptic basins (generally disynaptic), with the participation of two (or more) atomic valence shells and the monosynaptic ones, which correspond to electron lone-pairs. ELF calculations were carried out with the TopMod suite of programs. $^{44}$

A second approach, the atoms in molecules (AIM) theory, ${ }^{45,46}$ was also used in our bonding study. This theory is based on a topological analysis of the electron density, which permits to define a molecular graph as the ensemble of bond critical points (bcps), stationary points in which the electron density is minimum only in the direction of the bond, and bond paths. In general the electron density, as well as the energy density calculated at the bcps, give useful information on the strength and nature of the bond. For this purpose the AIMPAC series of programs was employed. ${ }^{47}$ These analyses were complemented with natural bond orbital (NBO) and Natural Resonance Theory (NRT) calculations. ${ }^{48}$ The former permits to describe the bonding in terms of localized hybrids and lone-pairs and, the second provides the weight of the different resonant structures that contribute to the stability of a given system. The Wiberg bond orders (BO) were also evaluated in the framework of the former approach. These calculations have been carried out with the NBO-5G series of programs. $^{49}$

\section{Results and Discussion}

The most stable tautomeric forms of uracil- $\mathrm{Ca}^{2+}$ and thiouracil- $\mathrm{Ca}^{2+}$ complexes have been plotted in Figure 1. 


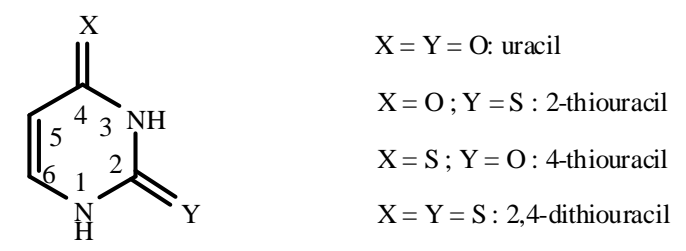

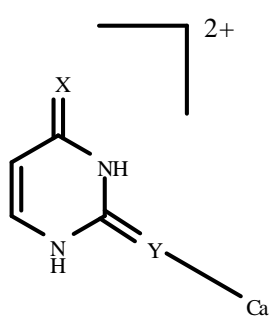

1

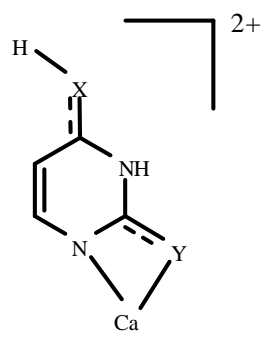

$3 \mathbf{b}$

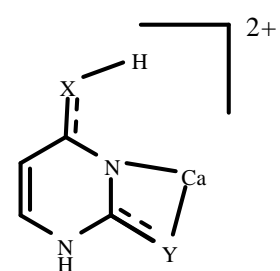

$2 \mathbf{a}$<smiles>CC[Te+]=c1cc[nH]c(=[V])[nH]1</smiles>

4

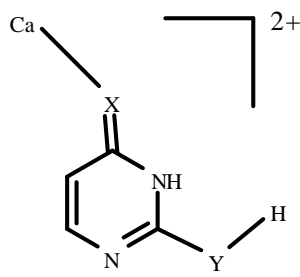

6a<smiles>[H][Y]=C1C=CNC2=[AlH]N12</smiles>

$\mathbf{2 b}$<smiles>[H][Y]=C1NC=CC(=N[CH])N1[CH]CC</smiles>

$5 \mathbf{a}$<smiles>[H][Y]c1nccc(=[V]Cl)[nH]1</smiles>

6b

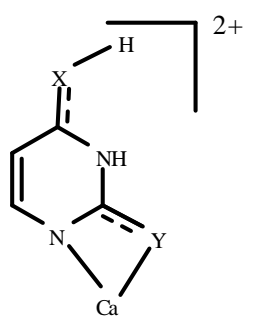

3a

$\mathbf{5 b}$

Figure 1. Schematic representation of the different tautomeric forms of uracil- and thiouracil- $\mathrm{Ca}^{2+}$ complexes

In what follows the heteroatoms bound to $\mathrm{C} 4$ and to $\mathrm{C} 2$ will be named $\mathrm{X}$ and $\mathrm{Y}$, respectively. When a given tautomer presents more than one conformer they were named by adding $\mathbf{a}$ or $\mathbf{b}$ to the number identifying the tautomer. Their relative energies are summarized in Table 1, whereas their total energies, ZPVE corrections and entropies are given in Table S1 of the supplementary information. In our theoretical survey we have considered more structures 
than those compiled in Figure 1, but structures like the ones shown in scheme 1, either lie very high in energy of finally collapse to one of the local minima shown in Figure 1.

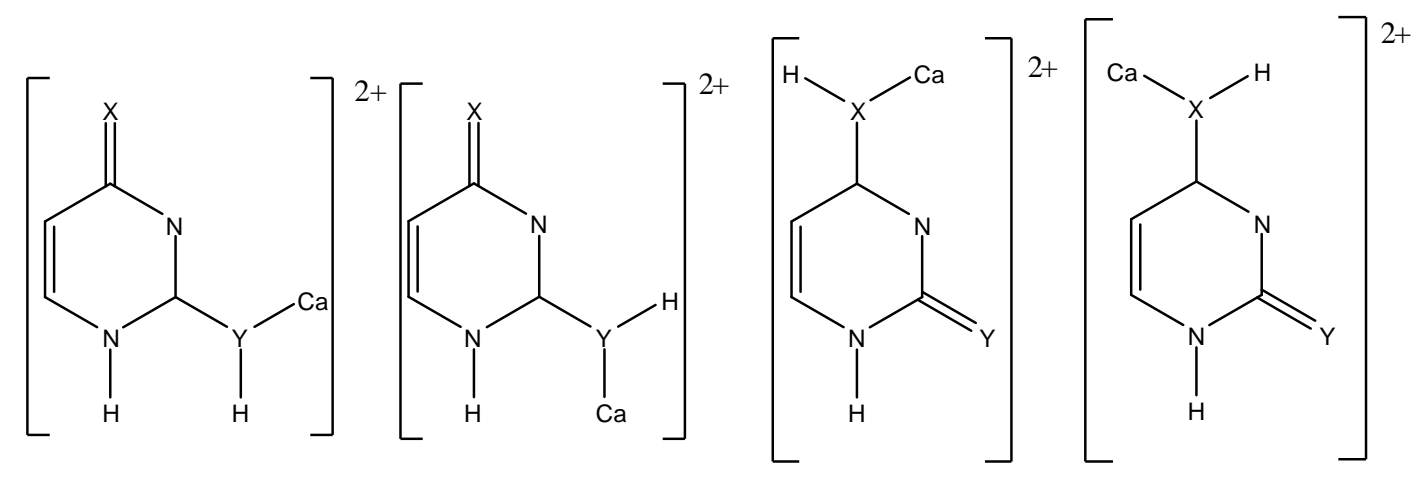

Scheme 1

\section{Geometries, relative stabilities and bonding}

The optimized geometries of all conformers considered in this work are given in Table S2 of the supplementary information. Although a detailed discussion of the optimized geometries is not one of the goals of this study, it is worth mentioning, that whereas the $\mathrm{C}=\mathrm{O}-\mathrm{Ca}$ angles are always equal to $180^{\circ}$, the $\mathrm{C}=\mathrm{S}-\mathrm{Ca}$ bond angles are systematically close to $123^{\circ}$, and the S-Ca bond does not lie in the plane of the molecule. These dissimilarities between $\mathrm{O}-\mathrm{Ca}^{2+}$ and $\mathrm{S}-\mathrm{Ca}^{2+}$ interactions were also found for other metal monocations, such as $\mathrm{Li}^{+}$and clearly reflect, the ionic character of the interaction, which will be discussed later. Assuming that the primary interaction is electrostatic, a suitable explanation of these dissimilarities was provided in terms of the characteristics of the molecular electrostatic potential and the average distance of the metal ion to the basic center. ${ }^{50}$ When the basic site is a carbonyl oxygen, the distance between the $\mathrm{O}$ nucleus and the electrostatic potential minima associated with the $\mathrm{O}$ lone-pairs is shorter than the typical dication-oxygen distance in the complex. This means that the metal dication moves along isopotential lines connecting the two minima, and finally it nests between them, because in this way it polarizes both lone- 
pairs simultaneously. For the sulfur atom, the distance between the minima of the electrostatic potentials and the S nucleus is similar to the S-metal ion distance, and therefore the metal cation is trapped in either of these minima.

It is also important to note that all attempts to locate $\pi$-type complexes, in which $\mathrm{Ca}^{2+}$ interacts with the double bonds in the ring failed for the three thiouracils because all these structures finally collapsed to the most stable adduct in which the metal interacts with the heteroatom X. For uracil, as it was already reported in the literature ${ }^{17}$, a $\pi$-type complexes actually exist as local minima, but it lies more than $250 \mathrm{~kJ} \mathrm{~mol}^{-1}$ above the most stable adduct. The same happens when trying to attach the metal ion to the $\mathrm{NH}$ groups. Only in the case of 2,4-dithiouracil, structure 7 (see Figure 2) was found to be a local minimum of the potential energy surface. Interestingly, these kinds of structures which are not stable for uracil were found to be also stable for all the selenouracils derivatives. ${ }^{51}$ More importantly, a 7-like structure was found to be the most stable adduct for 2,4-diselenouracil-Ca ${ }^{2+}$ complexes. As explained in ref. 51, two factors seem to be responsible for the enhanced stability of structures 7 when dealing with sulfur or selenium derivatives. On one hand, when oxygen is replaced by sulfur or selenium, which are less electronegative than oxygen, an accumulation of electron density on the N3 lone-pair occurs. On the other hand, and more importantly sulfur and selenium are much more polarizable than oxygen and structure 7 is stabilized because the two highly polarizable centers are close to the metal dication. As a matter of fact an inspection of the topology of the electron density shows the existence of bcps between the metal dication and both sulfur atoms (see Figure 2). 


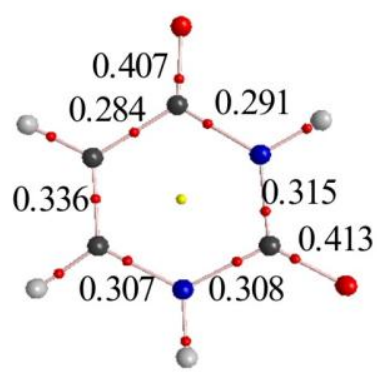

uracil

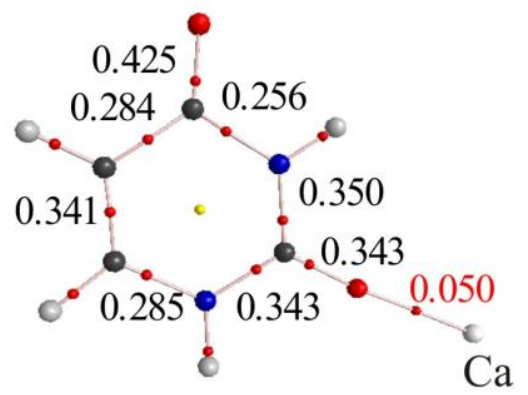

1

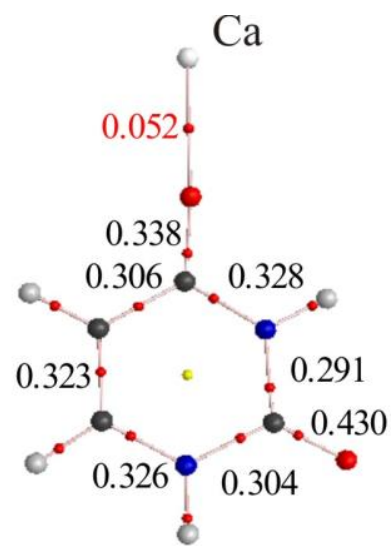

4

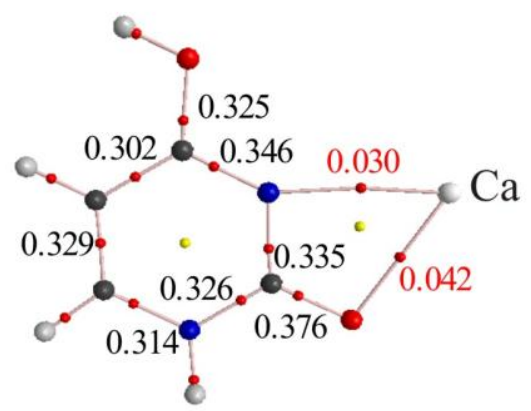

2b

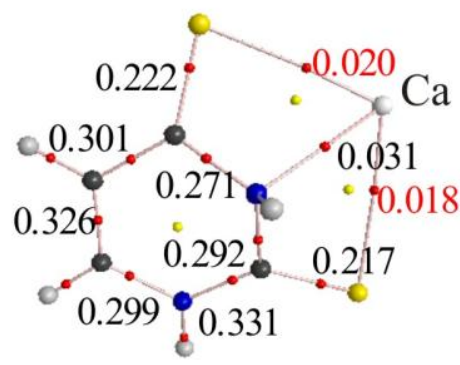

2,4-dithiouracil(7)

Figure 2. Molecular graphs of uracil, uracil- $\mathrm{Ca}^{2+}$ complexes, $\mathbf{1}, \mathbf{4}$ and $\mathbf{2 b}$ and 2,4-dithiouracil-Ca ${ }^{2+}$ complex 7. Electron densities at the bcps are in a.u.

Also the ELF shows the existence of disynaptic $\mathrm{V}(\mathrm{Ca}, \mathrm{S})$ basins which actually reflect the strong polarization undergone by the sulfur lone-pairs in the presence of the metal dication (see Figure 3). The fact that Se is more polarizable than sulfur explains why for the 2,4-diselenouracil structure 7 is the most stable adduct ${ }^{51}$ whereas for 2,4-dithiouracil is only the second more stable adduct. This difference in polarizability also explains that whereas for 2- and 4-selenouracil, structures 7 are local minima of the potential energy surface ${ }^{51}$ for 2and 4-thiouracil derivatives they are not. 


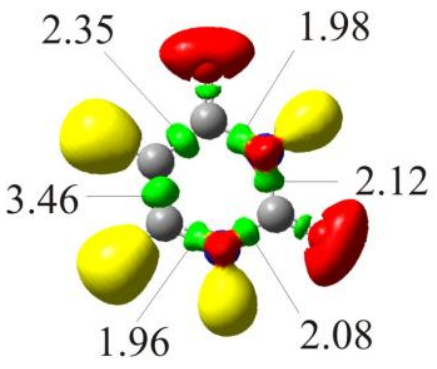

uracil

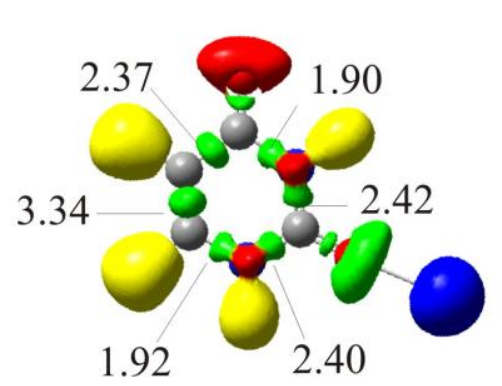

1

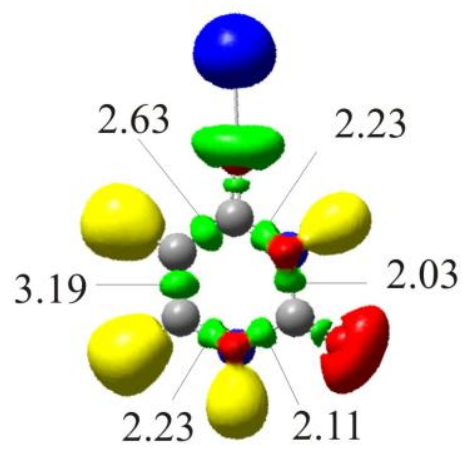

4

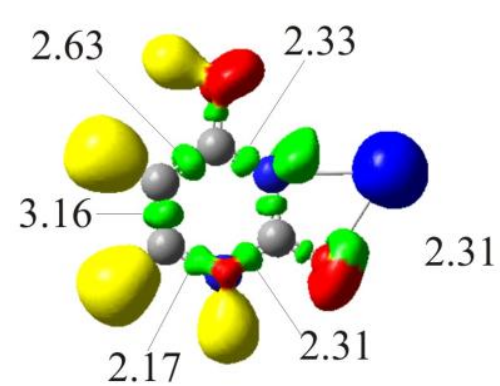

2b

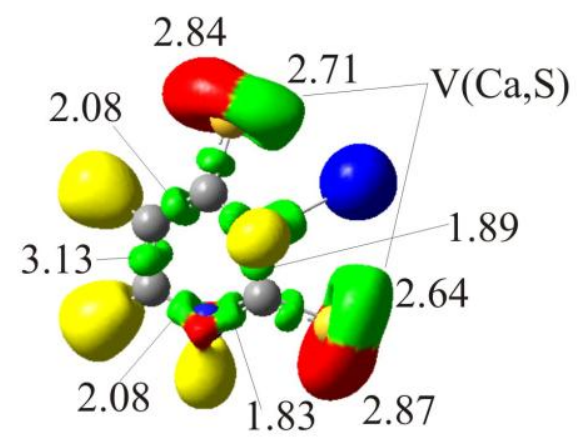

2,4-dithiouracil (7)

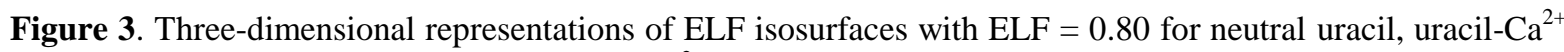
complexes, 1, $\mathbf{4}$ and $\mathbf{2 b}$ and 2,4-dithiouracil-Ca ${ }^{2+}$ complex 7. Yellow lobes correspond to V(N,H) and V(C,H) basins, red lobes correspond to $\mathrm{V}(\mathrm{N}), \mathrm{V}(\mathrm{O})$ and $\mathrm{V}(\mathrm{S})$ basins associated with $\mathrm{N}$, $\mathrm{O}$ and $\mathrm{S}$ lone-pairs, respectively. Green lobes correspond to $\mathrm{V}(\mathrm{C}, \mathrm{C}), \mathrm{V}(\mathrm{C}, \mathrm{N}), \mathrm{V}(\mathrm{C}, \mathrm{O}), \mathrm{V}(\mathrm{C}, \mathrm{S})$ and $\mathrm{V}(\mathrm{Ca}, \mathrm{S})$ basins. Blue lobes correspond to the $\mathrm{Ca}$ metal core. The populations of the different basins are also indicated.

The enhanced basicity of the heteroatom at position 4 (X) with respect to the heteroatom at position $2(\mathrm{Y})$ has been well documented in the literature for uracil and thiouracils. ${ }^{35,52-54}$ Recently, it has been also concluded, based on density functional theory calculations that this position is the most basic one in selenouracils, both when the reference acid is a proton ${ }^{55}$ or a $\mathrm{Ca}^{2+}$ dication. ${ }^{51}$ Hence, it is not surprising to find that for uracil and 2,4-dithiouracil, where both heteroatoms are identical, the attachment of $\mathrm{Ca}^{2+}$ to $\mathrm{X}$ is preferred by 41 and $31 \mathrm{~kJ} \mathrm{~mol}^{-1}$, respectively, with respect to attachment to $\mathrm{Y}$ (see Table 1). Note that the value of $438 \mathrm{~kJ} \mathrm{~mol}^{-1}$ obtained for uracil is slightly below the binding energy 
recently estimated at the B3LYP/6-311+G(2df,2p) level (451 kJ mol ${ }^{-1}$, Russo et al. JPCA $107,11533-11538(2003))$

Table 1. $\mathrm{Ca}^{2+}$ binding energies $\left(\mathrm{kJ} \mathrm{mol}^{-1}\right)$ of uracil and thiouracils for the adducts at basic sites $\mathrm{X}$ and $\mathrm{Y}$

\begin{tabular}{|c|c|c|}
\hline Compound & X & Y \\
\hline Uracil & 438 & 397 \\
\hline 2-thiouracil & 439 & 356 \\
\hline 4-thiouracil & 386 & 399 \\
\hline 2,4-dithiouracil & 388 & 358 \\
\hline
\end{tabular}

This preference to bind to $\mathrm{X}$ was traditionally attributed to the contribution of zwiterionic mesomeric forms which accumulate negative charge in this position. However, similar mesomeric forms accumulating negative charge at $\mathrm{Y}$ contribute also significantly to the stability of the neutral compound, so this factor alone cannot explain the preference of uracil and its derivatives to undergo the electrophilic attacks at X. A second important factor in favor of association to $\mathrm{X}$ is the electron density redistribution undergone by the system upon cation attachment, which is significantly different depending on the site where the cation enters. This is apparent when the ELF of complexes $\mathbf{1}$ and $\mathbf{4}$ are compared with that of the neutral compound (see Figure 3). Let us take uracil as a suitable example. On going from the neutral to complex $\mathbf{1}$, where the metal cation is bonded to $\mathrm{Y}$, the electron density remains strongly localized, and the populations of the basins associated with the C5-C6, C5-C4, C4$\mathrm{N} 3$ and C6-N1 hardly changed, the most significant changes affecting to the C2-N1 and C2$\mathrm{N} 3$ bonds. Conversely, association of the metal dication to $\mathrm{X}$ to yield complex $\mathbf{4}$, triggers a 
significant delocalization of the electron density, which involves a charge transfer from the C5-C6 basin, towards the C5-C4, C4-N3 and C6-N1 ones. This electron delocalization, which contributes to stabilize the molecular cation, is actually mirrored in a certain equalization of both the bond distances within the ring and the electron densities at the corresponding bcps (see Figure 2). This picture is also consistent with the Wiberg BOs. As shown in Table 2, in neutral uracil, C5-C6 has a significant double bond character, whereas the remaining bonds within the ring are essentially single bonds. The situation changes very little upon $\mathrm{Ca}^{2+}$ attachment to $\mathrm{Y}$, and only $\mathrm{C} 2-\mathrm{N} 3$ and $\mathrm{C} 2-\mathrm{N} 1$ slightly increase their double bond character. Conversely, when $\mathrm{Ca}^{2+}$ is attached to $\mathrm{X}$, the changes in the BOs are significant. The double bond character of C5-C6 decreases significantly, whereas it increases for $\mathrm{C} 5-\mathrm{C} 4, \mathrm{C} 6-\mathrm{C} 1$, and $\mathrm{C} 3-\mathrm{C} 4$, ratifying the significant charge delocalization produced by the $\mathrm{Ca}^{2+}$ polarization. Similar trends are also observed for 2-, 4- and 2,4-thiouracils.

Table 2. Wiberg bond orders for uracil and its $\mathrm{Ca}^{2+}$ adducts $\mathbf{1}$ and $\mathbf{4}$.

\begin{tabular}{|l|l|l|l|}
\hline Bond & Uracil & $\mathbf{1}$ (attached to Y) & $\mathbf{4}$ (attached to X) \\
\hline N1-C2 & 1.05 & 1.23 & 1.03 \\
\hline C2-N3 & 1.10 & 1.29 & 1.00 \\
\hline N3-C4 & 1.04 & 0.98 & 1.22 \\
\hline C4-C5 & 1.09 & 1.09 & 1.28 \\
\hline C5-C6 & 1.70 & 1.74 & 1.50 \\
\hline C6-N1 & 1.14 & 1.06 & 1.28 \\
\hline
\end{tabular}

It is also worth noting that the $\mathrm{Ca}^{2+}$ binding energy is $50 \mathrm{~kJ} \mathrm{~mol}^{-1}$ larger for uracil than for 2,4-dithiouracil, in spite of the fact that thiocarbonyl derivatives exhibit greater gas- 
phase proton affinities than their carbonyl counterparts. This confirms, as it has been shown previously in the literature ${ }^{51}$, the clear preference for $\mathrm{Ca}^{2+}$ to attach to oxygen, rather than to sulfur or selenium. As a matter of fact, the calculated $\mathrm{Ca}^{2+}$ binding energy of urea $(449 \mathrm{~kJ}$ $\left.\mathrm{mol}^{-1}\right)$ is larger than that of thiourea $\left(404 \mathrm{~kJ} \mathrm{~mol}^{-1}\right)$ or selenourea $\left(408 \mathrm{~kJ} \mathrm{~mol}^{-1}\right)$. Similarly, acetamide also binds $\mathrm{Ca}^{2+}$ stronger than thioacetamide or selenoacetamide. ${ }^{51}$ This preference for $\mathrm{Ca}^{2+}$ to bind to oxygen explains the significant increase in the gap between adducts 4 and 1 on going from uracil to 2-thiouracil, because both effects, the enhanced basicity of $\mathrm{X}$ and the preference to bind an oxygen atom, go in the same direction. Conversely, for 4-thiouracil both effects go in opposite direction, although the preference to bind to oxygen slightly dominates, and structure $\mathbf{1}$ is found to be slightly more stable than $\mathbf{4}$.

Also interestingly, the nature of the second heteroatom has an almost negligible influence on the $\mathrm{Ca}^{2+}$ affinity of both carbonyl and thiocarbonyl groups. Indeed, the $\mathrm{Ca}^{2+}$ binding energy to the oxygen of 2-thiouracil is $1 \mathrm{~kJ} \mathrm{~mol}^{-1}$ larger than that of uracil, and the $\mathrm{Ca}^{2+}$ binding energy to the sulfur atom is $3 \mathrm{~kJ} \mathrm{~mol}^{-1}$ smaller than that of $\mathrm{X}$ in 2,4-dithiouracil. Similarly, the sulfur $\mathrm{Ca}^{2+}$ affinity of 4-thiouracil is $3 \mathrm{~kJ} \mathrm{~mol}^{-1}$ smaller than that of 2,4dithiouracil, and its oxygen $\mathrm{Ca}^{2+}$ binding energy $2 \mathrm{~kJ} \mathrm{~mol}^{-1}$ higher than that of $\mathrm{Y}$ in uracil.

There are however some dissimilarities in the nature of the $\mathrm{O}-\mathrm{Ca}^{2+}$ and the $\mathrm{S}-\mathrm{Ca}^{2+}$ interactions. Independently of the nature of the basic site, these interactions are essentially ionic, as indicated by the small value of the electron density at both the O-Ca and the S-Ca bcps (typically around 0.05 a.u. for O-Ca bonds and 0.03 for S-Ca bonds), and in the positive value of the energy density, as it corresponds to the interaction between two close-shell systems. Also consistently, the NBO analysis describes these complexes as the interaction between the polarized uracil or thiouracil moiety and $\mathrm{Ca}^{2+}$. However, while in $\mathrm{O}-\mathrm{Ca}^{2+}$ interactions the natural charge of the metal is close to +2.0 , in $\mathrm{S}-\mathrm{Ca}^{2+}$ interactions there is a small charge transfer from the sulfur lone-pairs towards the $4 \mathrm{~s}$ empty orbital in $\mathrm{Ca}^{2+}$, 
reflecting the larger polarizability of sulfur. Consequently, in these cases the net natural charge on $\mathrm{Ca}$ is about +1.8 . The strong polarization undergone by the base upon $\mathrm{Ca}^{2+}$ association is nicely reflected in the ELF, which shows a significant increase in the population of the $\mathrm{V}(\mathrm{O})$ (or the $\mathrm{V}(\mathrm{S})$ ) basin of the basic site upon $\mathrm{Ca}^{2+}$ attachment. More importantly, when $\mathrm{Ca}^{2+}$ is bonded to a thiocarbonyl group, a disynaptic $\mathrm{V}(\mathrm{S}, \mathrm{Ca})$ basin is located, showing that in this case the covalent character of the interaction is not negligible.

\section{Tautomerization processes. Catalytic effect of $\mathrm{Ca}^{2+}$ association}

Since uracil and its thioderivatives only exist as dioxo and oxo-thione forms in the gas phase, only complexes 1, 4 and 7 can be formed by direct association of $\mathrm{Ca}^{2+}$ to the available basic sites. However, among all the possible tautomers included in Figure 1, the aforementioned adducts are the least stable complexes (see Table 3 and Figure 4), which means that $\mathrm{Ca}^{2+}$ association completely alter the stability trends observed for the isolated neutrals. This had been already pointed out for uracil by Russo et al., even though the most stable tautomeric form (2b) had not been studied. (Ref Russo)

Table 3. Relative energies $\left(\mathrm{kJ} \mathrm{mol}^{-1}\right)$ of the different tautomers of uracil- and thiouracil- $\mathrm{Ca}^{2+}$ complexes

\begin{tabular}{lcccc}
\hline Tautomer & Uracil & 2-thiouracil & 4-thiouracil & 2,4-dithiouracil \\
\hline $\mathbf{1}$ & 91 & 137 & 106 & 147 \\
$\mathbf{2 a}$ & 23 & 33 & 13 & 18 \\
$\mathbf{2 b}$ & 0 & 0 & 0 & 0 \\
$\mathbf{3 a}$ & 30 & 31 & 8 & 5 \\
$\mathbf{3 b}$ & 14 & 16 & 4 & 2 \\
$\mathbf{4}$ & 50 & 54 & 119 & 117 \\
$\mathbf{5 a}$ & 30 & 10 & 58 & - \\
& & & & \\
$\mathbf{5 b}$ & 30 & 0.4 & 42 & $17^{\mathrm{a}}$ \\
$\mathbf{6 a}$ & 118 & 66 & 137 & 131 \\
$\mathbf{6 b}$ & 120 & 78 & 174 & 122 \\
$\mathbf{7}$ & - & - & - & 126
\end{tabular}




\footnotetext{
${ }^{\text {a }}$ For 2,4-dithiouarcil structure 5a is not a stationary point of the PES and collapses to
} structure $\mathbf{5 b}$

The formation of enol or enthiol forms by $1,3 \mathrm{H}$ shifts from one of the $\mathrm{NH}$ groups toward $\mathrm{X}$ or $\mathrm{Y}$, facilitate the interaction of the metal dication with the N-pyridine-like nitrogen atoms, which have a rather big intrinsic basicity and with the neighbor $\mathrm{X}$ or $\mathrm{Y}$ heteroatom. The possibility of polarizing two basic sites simultaneously enhances the stability of these complexes which become more stable than adducts $\mathbf{1 , 4}$ or $\mathbf{7}$. Actually, tautomers $\mathbf{6}$ in which this kind of arrangement is not possible are the least stable structures (see Table 3). Furthermore, as it has been found before for thymine- $\mathrm{M}^{2+}(\mathrm{M}=\mathrm{Ni}, \mathrm{Cu}, \mathrm{Zn})$ complexes ${ }^{56}$ the aromatization of the enolic ring is an additional factor which contributes a lot to the stabilization of the enol or enthiol forms. This aromatization is clearly reflected in the equalization of the bond distances on going from adduct $\mathbf{1}$ to complex $\mathbf{2} \mathbf{b}$, which is the global minimum of the $\mathrm{Ca}^{2+}$-uracil and $\mathrm{Ca}^{2+}$-thiouracils PESs. Coherently, there is a parallel equalization of the electron densities at the bcps, and of the bond orders. Furthermore, the nucleus independent chemical shift (NICS) evaluated in a point $1 \AA$ above the ring center, which can be considered a good index to measure the aromaticity of a system, is for complex $\mathbf{2 b}$ twice as large, in absolute value ( $-4.85 \mathrm{ppm})$ than for complex $\mathbf{1}(-2.40 \mathrm{ppm})$. It is worth noting that in all cases the global minimum of the potential energy surface corresponds to structure $\mathbf{2 b}$, in which $\mathrm{Ca}^{2+}$ interacts simultaneously with $\mathrm{Y}$ and $\mathrm{N} 3$, the second more stable being tautomer $\mathbf{3 b}$, in which $\mathrm{Ca}^{2+}$ bridges between $\mathrm{Y}$ and N1. 2-thiouracil is an exception to this general trend, because for this compound tautomer $\mathbf{5 b}$, in which the metal interacts with $\mathrm{N} 3$ and $\mathrm{X}$ is almost degenerated with tautomer $\mathbf{2 b}$. It is interesting to note, that conversely, for 4-thiouracil the energy gap between forms $\mathbf{2} \mathbf{b}$ and $\mathbf{5 b}$ is the largest of the whole set compounds considered. Both findings ratified nicely the preference of $\mathrm{Ca}^{2+}$ to bind oxygen rather than sulfur. 


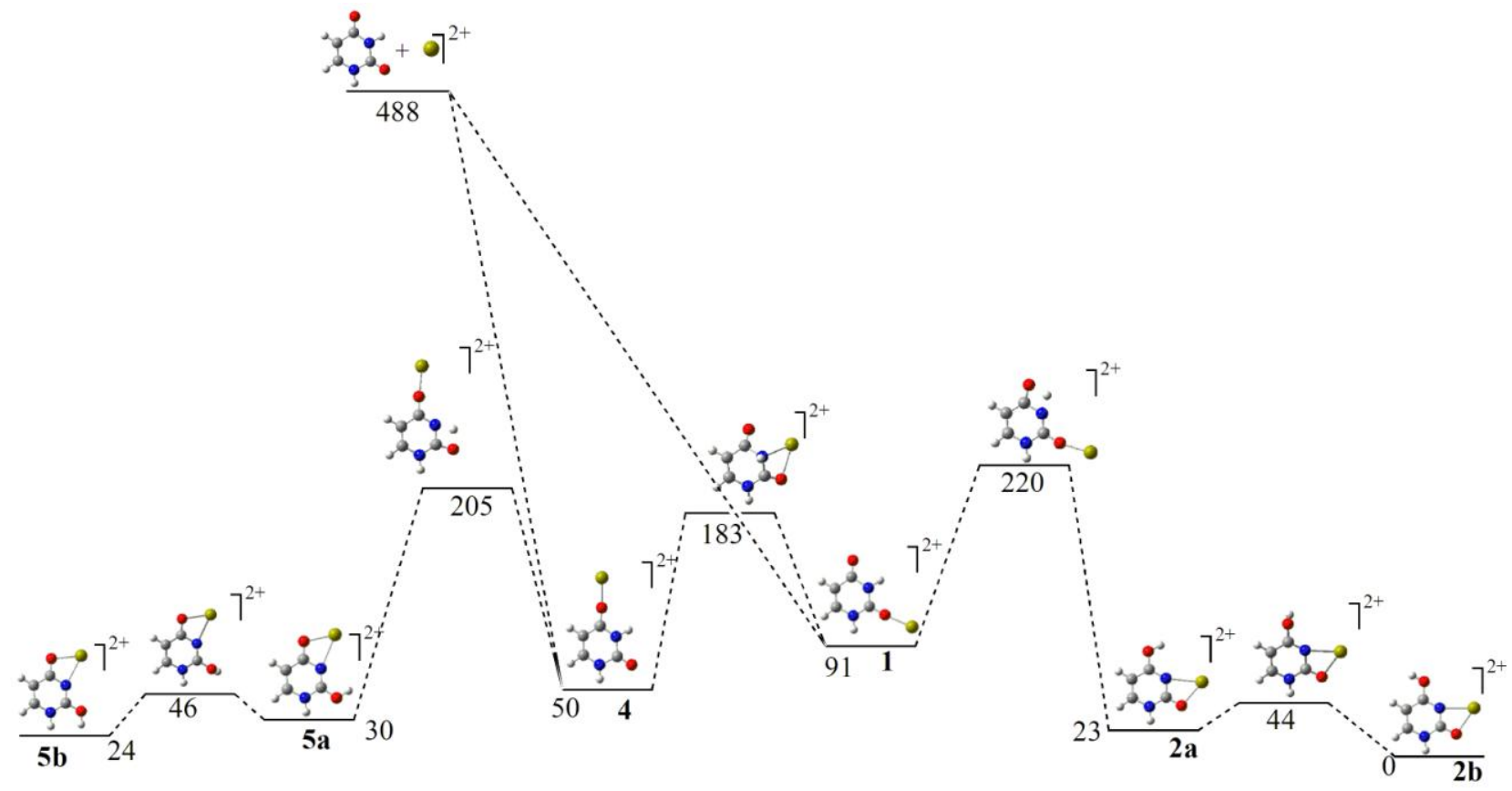

(a)

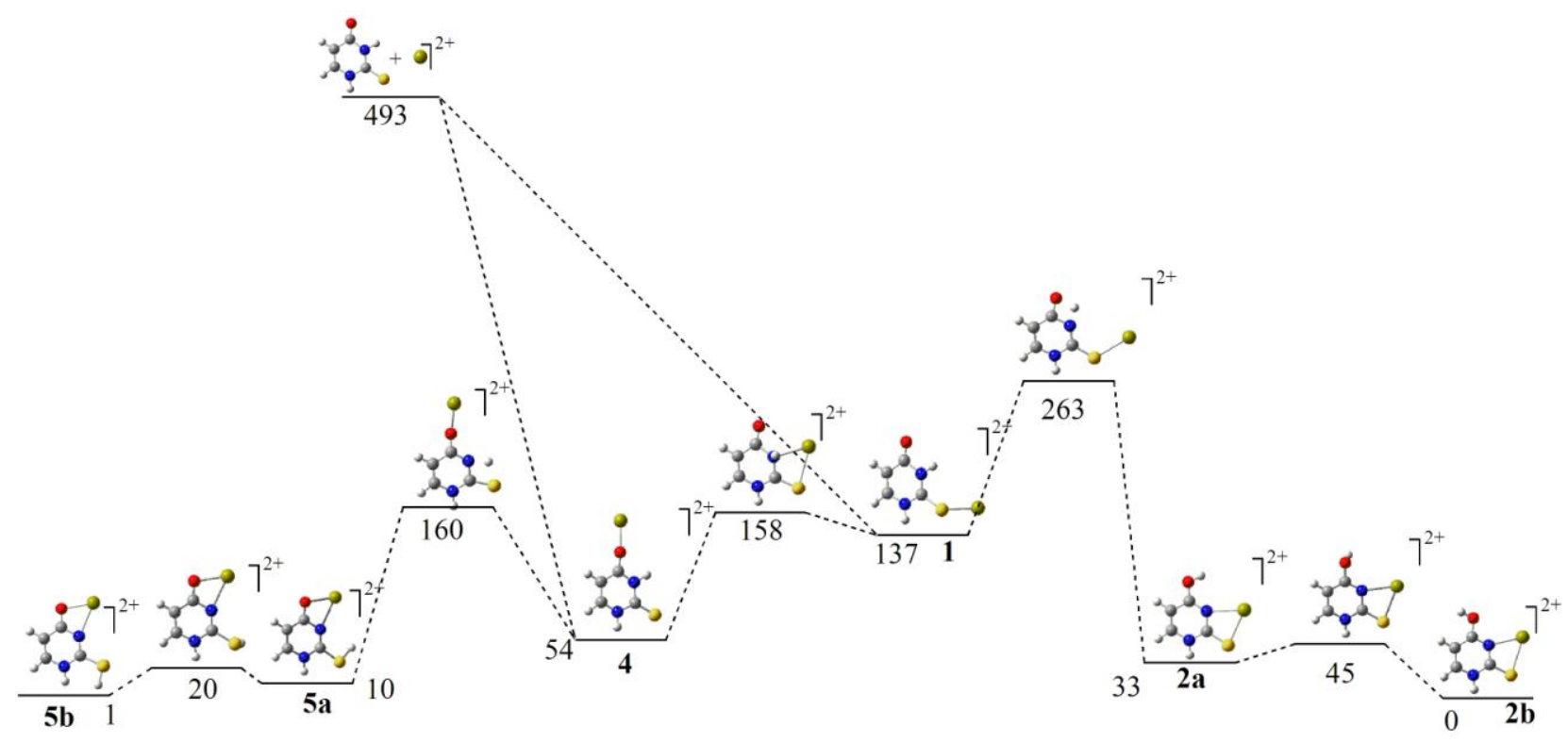

(b) 


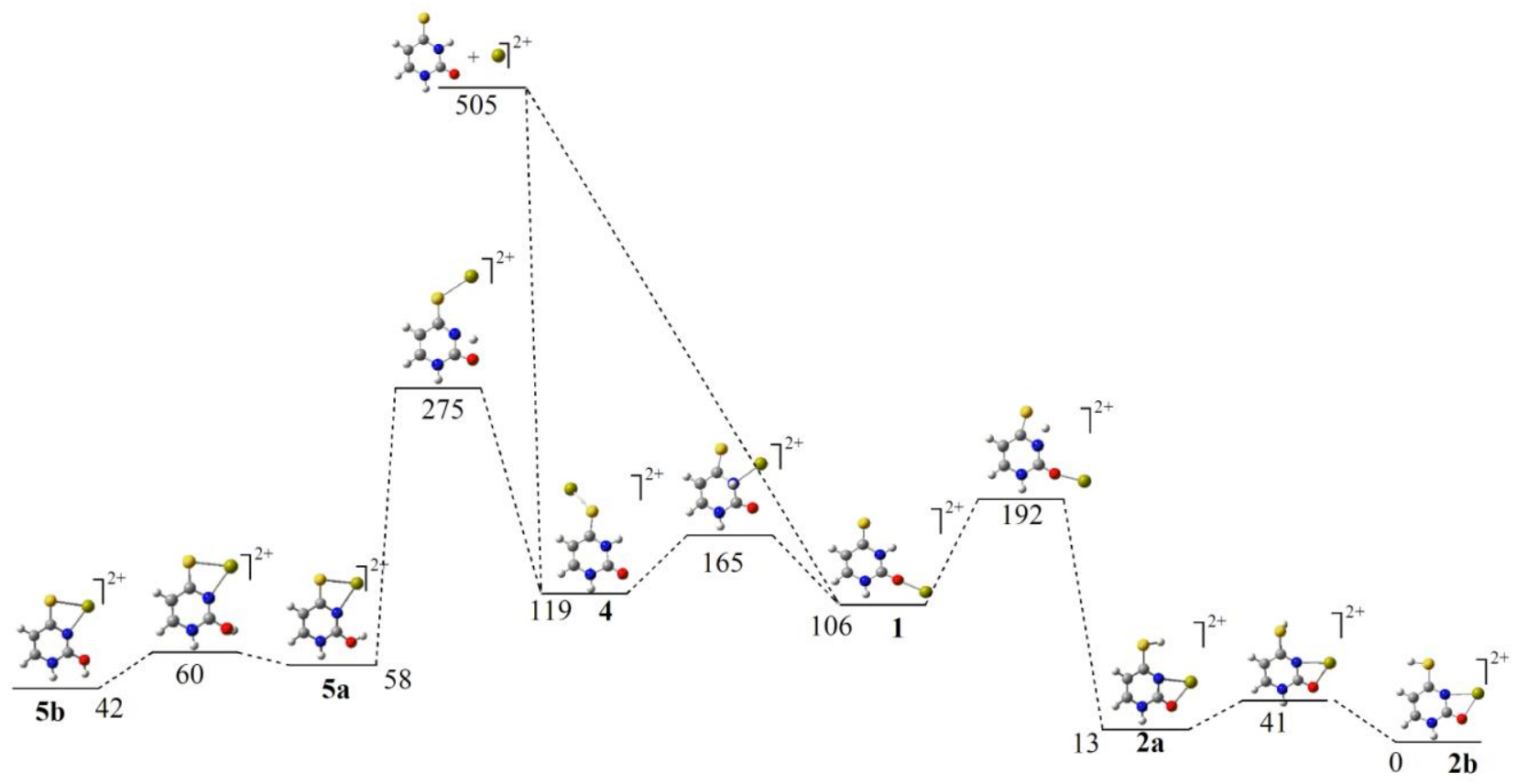

(c)

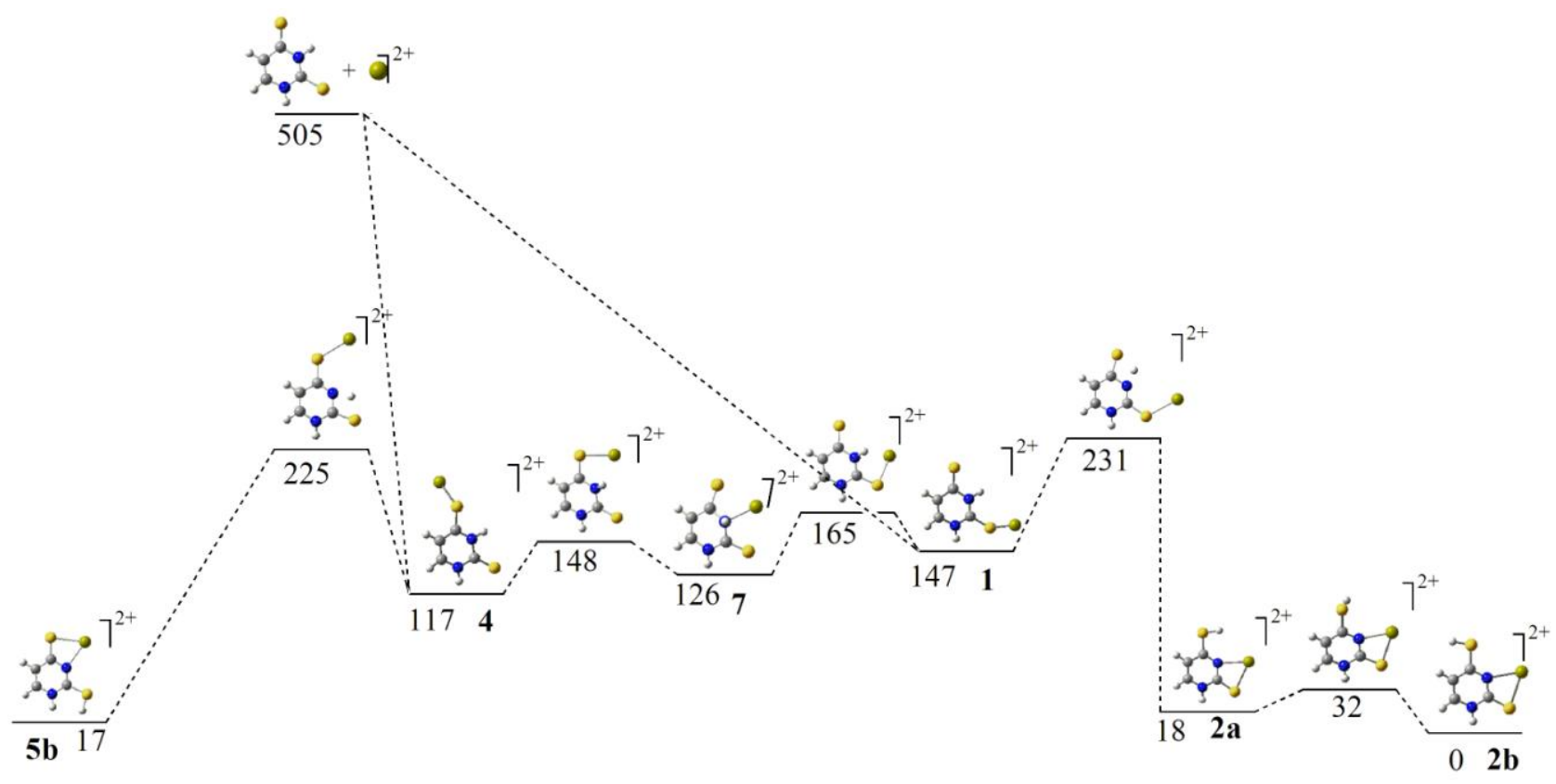

(d)

Figure 4: Energy profiles for the isomerization process of : a) uracil-Ca ${ }^{2+}$ adducts; b) 2-thiouracil-Ca ${ }^{2+}$ adducts; c) 4-thiouracil- $\mathrm{Ca}^{2+}$ adducts; d) 2,4-dithiouracil- $\mathrm{Ca}^{2+}$ adducts . Relative energies are in $\mathrm{kJ} \mathrm{mol}^{-1}$.

Tautomers $\mathbf{2}$ and $\mathbf{5}$ can be directly obtained from adducts $\mathbf{1}$ and $\mathbf{4}$ by a single 1,3H transfer, whereas a multi-step mechanism is required to connect $\mathbf{1}$ and $\mathbf{4}$ with tautomers $\mathbf{3}$. The energy profiles associated with the $\mathbf{1} \rightarrow \mathbf{2}, \mathbf{1} \rightarrow \mathbf{4}$ and $\mathbf{4} \rightarrow \mathbf{5}$ tautomerization processes have 
been plotted in Figures 4a-d. The first important feature is that all tautomerization barriers are well below the entrance channel. This means that the complex formed by addition of $\mathrm{Ca}^{2+}$ to any of the oxo or thione forms of the compounds under scrutiny will have enough internal energy to overpass these barriers. The important consequence is that, although for the neutral systems only the oxo-thione forms are to be found in the gas-phase, for the $\mathrm{Ca}^{2+}$ complexes, all tautomeric forms are energetically accessible, the enol/enthiol forms being the most stable. Consequently, these tautomeric forms might be formed experimentally in the gas phase, notably during the electrospray ionization process preceding mass spectrometry analysis, as recently demonstrated for protonated uracil. ${ }^{57}$ Also importantly, the activation barriers involved in these tautomerization processes are much lower than those calculated for the isolated neutral compounds. ${ }^{35}$ For example, for 2-thiouracil the $\mathbf{1 - 2}$ tautomerization barrier decreases $28 \%$, whereas the 4-5 decreases 39\%. For 4- and 2,4-dithiouracil these decreases are $47 \%$ and $37 \%$, respectively for the $\mathbf{1 - 2}$ tautomerization process and $39 \%$ and $35 \%$, respectively for the $\mathbf{4 - 5}$ tautomerization process.

\section{Conclusions}

From our theoretical survey of the interaction between uracil and its thio-derivatives with $\mathrm{Ca}^{2+}$ in the gas phase, we can conclude that:

a) for uracil and 2,4-dithiouracil, where the two basic sites are the same, $\mathrm{Ca}^{2+}$ attachment to the heteroatom at position 4 is preferred, due essentially to a significant electron delocalization within the six-membered ring when the metal binds to $\mathrm{X}$, which is not observed when it is attached to Y.

b) For those systems where both types of basic centers, a carbonyl or a thiocarbonyl group, are present, $\mathrm{Ca}^{2+}$ association to the oxygen is always favored with respect to association to sulfur. 
c) The most stable complex corresponds systematically to structure $\mathbf{2 b}$, in which the metal dication bridges between $\mathrm{Y}$ of the 4-enol (or the 4-enthiol) tautomer and the dehydrogenated ring nitrogen, N3. The enhanced stability of these enol forms is twofolded. On the one hand, the structure of the enol (enethiol) facilitates the interaction of $\mathrm{Ca}^{2+}$ with the $\mathrm{N}$-pyridine-like nitrogen atom and with the neighbor $\mathrm{X}$ or $\mathrm{Y}$ heteroatom, polarizing both basic sites simultaneously. On the other hand, a significant aromatization of the six-membered ring takes place.

d) $\mathrm{Ca}^{2+}$ association has a clear catalytic effect on the tautomerization processes which connect the oxo-thione forms with the enol-enthiol tautomers. Hence, although the enol-enthiol tautomers of uracil and its thio derivatives should not be observed in the gas phase, the corresponding $\mathrm{Ca}^{2+}$ complexes are the most stable species and might be accessible experimentally, because the tautomerization barriers are smaller than the $\mathrm{Ca}^{2+}$ binding energies.

Acknowledgements. This work has been partially supported by the DGI Project No. CTQ2006-08558/BQU, by the Project MADRISOLAR, Ref.: S-0505/PPQ/0225 of the Comunidad Autónoma de Madrid and by Consolider on Molecular Nanoscience CSD200700010. CT acknowledges a FPI grant from the Ministerio de Educación y Ciencia of Spain. A generous allocation of computing time at the CCC of the UAM is also acknowledged.

\section{References}

1. $\quad$ M. Remko and B. M. Rode, Chem. Phys. Lett., 2000, 316, 489-494.

2. I. Corral, O. Mó, M. Yáñez, J.-Y. Salpin, J. Tortajada and L. Radom, J. Phys. Chem. A, 2004, 108, 10080-10088. 
3. M. Belcastro, T. Marino, N. Russo and M. Toscano, J. Mass Spectrom., 2005, 40, 300-306.

4. T. Dudev, L. Y. Chang and C. Lim, J. Am. Chem. Soc., 2005, 127, 4091-4103.

5. I. Corral, O. Mó, M. Yáñez, J. Y. Salpin, J. Tortajada, D. Moran and L. Radom, Chem. Eur. J, 2006, 12, 6787-6796.

6. R. N. Allen, M. K. Shukla, J. V. Burda and J. Leszczynski, J. Phys. Chem. A, 2006, 110, 6139-6144.

7. R. N. Allen, M. K. Shukla and J. Leszczynski, Int. J. Quant. Chem. , 2006, 106, 2366-2372.

8. C. Trujillo, O. Mó, M. Yáñez, J. Y. Salpin and J. Tortajada, ChemPhysChem, 2007, 8, 1330.

9. J. Andersson, K. Hauser, E. L. Karjalainen and A. Barth, Biophys. J., 2008, 94, 600611.

10. C. Trujillo, O. Mó, M. Yáñez, J. Tortajada and J.-Y. Salpin, J. Phys. Chem. B, 2008, 112, 5479-5486.

11. J. V. Burda, J. Sponer, J. Leszczynski and P. Hobza, J. Phys. Chem. B, 1997, 101, 9670-9677.

12. J. Sponer, J. V. Burda, M. Sabat, J. Leszczynski and P. Hobza, J. Phys. Chem. A, 1998, 102, 5951-5957.

13. B. Song, J. Zhao, R. Griesser, C. Meiser, H. Sigel and B. Lippert, Chem. Eur. J. , 1999, 5, 2374-2387.

14. J. Sponer, M. Sabat, J. V. Burda, J. Leszczynski and P. Hobza, J. Phys. Chem. B, $1999, \mathbf{1 0 3}, 2528-2534$.

15. S. R. Herron, R. D. Scavetta, M. Garrett, M. Legner and F. Jurnak, J. Bio. Chem., 2003, 278, 12271-12277. 
16. N. Russo, M. Toscano and A. Grand, J. Phys. Chem. A, 2003, 107, 11533-11538.

17. W. L. Zhu, X. M. Luo, C. M. Puah, X. J. Tan, J. H. Shen, J. D. Gu, K. X. Chen and H. L. Jiang, J. Phys. Chem. A, 2004, 108, 4008-4018.

18. J. Poater, M. Sodupe, J. Bertran and M. Sola, Mol. Phys., 2005, 103, 163-173.

19. A. S. Reddy and G. N. Sastry, J. Phys. Chem. A, 2005, 109, 8893-8903.

20. M. Remko and B. M. Rode, J. Phys. Chem. A, 2006, 110, 1960-1967.

21. I. Nicolas and M. Castro, J. Phys. Chem. A, 2006, 110, 4564-4573.

22. H. C. Liu, L. Zhang, P. Li, R. I. Cukier and Y. X. Bu, Chemphyschem, 2007, 8, 304314.

23. N. G. Tsierkezos, D. Schroder and H. Schwarz, Int. J. Mass Spectrom., 2004, 235, $33-42$.

24. S. Guillaumont, J. Tortajada, J.-Y. Salpin and A. M. Lamsabhi, Int. J. Mass Spectrom., 2005, 243, 279.

25. A. M. Lamsabhi, M. Alcamí, O. Mó, M. Yáñez, J. Tortajada and J. Y. Salpin, ChemPhysChem, 2007, 8, 181-187.

26. A. M. Lamsabhi, O. Mó, M. Yáñez, M. Alcamí and J. Tortajada, ChemPhysChem, $2004,5,1871$.

27. A. M. Lamsabhi, M. Alcamí, O. Mó, M. Yáñez and J. Tortajada, J. Phys. Chem. A, 2006, 110, 1943-1950.

28. P. Jayaweera, A. T. Blades, M. G. Ikonomou and P. Kebarle, J. Am. Chem. Soc., $1990, \mathbf{1 1 2}, 2452-2454$.

29. D. Schröder, Angew. Chem. Int. Ed., 2004, 43, 1329-1331.

30. W. Saenger, Principles of Nucelic Acid Structure, Springer, New York, 1984.

31. M. J. Scanlan and I. H. Hillier, J. Am. Chem. Soc., 1984, 106, 3737-3745.

32. A. Les and L. Adamowicz, J. Am. Chem. Soc., 1990, 112, 1504-1509. 
33. J. Leszczynski and K. Lammertsma, J. Phys. Chem., 1991, 95, 3128-3132.

34. Y. V. Rubin, Y. Morozov, D. Venkateswarlu and J. Leszczynski, J. Phys. Chem. A, 1998, 102, 2194-2200.

35. M. Lamsabhi, M. Alcamí, O. Mó, W. Bouab, M. Esseffar, J. L. M. Abboud and M. Yáñez, J. Phys. Chem. A, 2000, 104, 5122-5130.

36. S. Millefiori and A. Alparone, Chem. Phys., 2004, 303, 27-36.

37. A. D. Becke, J. Chem. Phys., 1993, 98, 1372-1377.

38. C. Lee, W. Yang and R. G. Parr, Phys. Rev. B, 1988, 37, 785-789.

39. M. J. Frisch, G. W. Trucks, H. B. Schlegel, G. E. Scuseria, M. A. Robb, J. R. Cheeseman, V. G. Zakrzewski, J. J. A. Montgomery, T. Vreven, K. N. Kudin, J. C. Burant, J. M. Millam, S. S. Iyengar, J. Tomasi, V. Barone, B. Mennucci, M. Cossi, G. Scalmani, N. Rega, G. A. Petersson, H. Nakatsuji, M. Hada, M. Ehara, K. Toyota, R. Fukuda, J. Hasegawa, M. Ishida, T. Nakajima, Y. Honda, O. Kitao, C. Adamo, J. Jaramillo, R. Gomperts, R. E. Stratmann, O. Yazyev, J. Austin, R. Cammi, C. Pomelli, J. Ochterski, P. Y. Ayala, K. Morokuma, G. A. Voth, P. Salvador, J. J. Dannenberg, V. G. Zakrzewski, S. Dapprich, A. D. Daniels, M. C. Strain, O. Farkas, D. K. Malick, A. D. Rabuck, K. Raghavachari, J. B. Foresman, J. V. Ortiz, Q. Cui, A. G. Baboul, S. Clifford, J. Cioslowski, B. B. Stefanov, G. Liu, A. Liashenko, P. Piskorz, I. Komaromi, R. L. Martin, D. J. Fox, T. Keith, M. A. Al-Laham, C. Y. Peng, A. Nanayakkara, M. Challacombe, P. M. W. Gill, B. Johnson, W. Chen, M. W. Wong, C. Gonzalez and J. A. Pople, Gaussian03, Revision E.01, (2003) Gaussian, Inc., Wallingford CT.

40. I. Corral, O. Mó, M. Yáñez, A. Scott and L. Radom, J. Phys. Chem. A, 2003, 107, 10456-10461.

41. A. P. Scott and L. Radom, J. Phys. Chem., 1996, 100, 16502-16513. 
42. A. D. Becke and K. E. Edgecombe, J. Chem. Phys., 1990, 92, 5397-5403.

43. B. Silvi and A. Savin, Nature, 1994, 371, 683-686.

44. S. Noury, X. Krokidis, F. Fuster and B. Silvi, Comput. Chem., 1999, 23, 597-604.

45. R. F. W. Bader, Atoms in Molecules. A Quantum Theory, Clarendon Press, Oxford, 1990.

46. C. F. Matta and R. J. Boyd, The Quantum Theory of Atoms in Molecules, Wiley-VCH Verlag GmbH \& Co. KGaA, Weinheim, 2007.

47. R. F. W. Bader and J. R. Cheeseman, AIMPAC Program, (2000).

48. A. E. Reed, L. A. Curtiss and F. Weinhold, Chem. Rev., 1988, 88, 899-926.

49. E. D. Glendening, J. K. Badenhoop, A. E. Reed, J. E. Carpenter, J. A. Bohmann, C. M. Morales and F. Weinhold, NBO 5.G. , (2004) Theoretical Chemistry Institute, University of Wisconsin

Madison, WI

50. M. Alcamí, O. Mó and M. Yáñez, in Molecular Electrostatic Potentials: Concepts and Applications, eds. J. S. Murray and K. Sen, Elsevier, Amsterdam, Editon edn., 1996, vol. 3, pp. 407-456.

51. A. M. Lamsabhi, O. Mó, M. Yáñez and R. J. Boyd, J. Chem. Theo. Comput., 2008, in press.

52. A. R. Katritzky, G. Baykut, S. Rachwal, M. Szafran, K. C. Caster and J. Eyler, J. Chem. Soc. Perkin Trans. 2, 1989, 1499-1506.

53. M. T. Nguyen, A. K. Chandra and T. Zeegers-Huyskens, J. Chem. Soc. Faraday Trans., 1998, 94, 1277-1280.

54. M. A. Kurinovich, L. M. Phillips, S. Sharma and J. K. Lee, Chem. Commun. , 2002, 2354-2355.

55. C. Trujillo, O. Mó and M. Yáñez, ChemPhysChem, 2008, in press. 
56. E. Rincón, M. Yáñez, A. Toro-Labbé and O. Mó, Phys. Chem. Chem. Phys., 2007, 9, 2531-2537.

57. J. Y. Salpin, S. Guillaumont, J. Tortajada, L. MacAleese, J. Lemaire and P. Maitre, Chemphyschem, 2007, 8, 2235-2244.

\section{Figure Captions}

Figure 1. Schematic representation of the different tautomeric forms of uracil- and thiouracil- $\mathrm{Ca}^{2+}$ complexes

Figure 2. Molecular graphs of uracil, uracil-Ca ${ }^{2+}$ complexes, 1, 4 and $\mathbf{2 b}$ and 2,4dithiouracil-Ca ${ }^{2+}$ complex 7. Electron densities at the bcps are in a.u.

Figure 3. Three-dimensional representations of ELF isosurfaces with ELF $=0.80$ for neutral uracil, uracil- $\mathrm{Ca}^{2+}$ complexes, 1,4 and $2 \mathrm{~b}$ and 2,4-dithiouracil-Ca2+ complex 7. Yellow lobes correspond to $\mathrm{V}(\mathrm{N}, \mathrm{H})$ and $\mathrm{V}(\mathrm{C}, \mathrm{H})$ basins, red lobes correspond to $\mathrm{V}(\mathrm{N}), \mathrm{V}(\mathrm{O})$ and $\mathrm{V}(\mathrm{S})$ basins associated with N, O and S lone-pairs, respectively. Green lobes correspond to $\mathrm{V}(\mathrm{C}, \mathrm{C}), \mathrm{V}(\mathrm{C}, \mathrm{N}), \mathrm{V}(\mathrm{C}, \mathrm{O}), \mathrm{V}(\mathrm{C}, \mathrm{S})$ and $\mathrm{V}(\mathrm{Ca}, \mathrm{S})$ basins. Blue lobes correspond to the Ca metal core. The populations of the different basins are also indicated.

Figure 4: Energy profiles for the isomerization process of : a) uracil-Ca ${ }^{2+}$ adducts; b) 2thiouracil- $\mathrm{Ca}^{2+}$ adducts; c) 4-thiouracil-Ca ${ }^{2+}$ adducts; d) 2,4-dithiouracil-Ca ${ }^{2+}$ adducts . Relative energies are in $\mathrm{kJ} \mathrm{mol}^{-1}$. 